\title{
La PNC de El Salvador durante los gobiernos del FMLN
}

Edgar Baltazar Landeros

\begin{abstract}
RESUMEN: Los Acuerdos de Paz de 1992 instauraron una nueva institucionalidad para El Salvador, incluyendo una nueva policía. La PNC nació con los parámetros de la doxa neoliberal sobre la función policial democrática, pero, a lo largo de la posguerra, la policía no ha cumplido con dichos parámetros democráticos. Durante los gobiernos del FMLN (2009 - 2019), la PNC no logró mejorar su desarrollo institucional y mantuvo una guerra contra las pandillas como agenda monotemática.
\end{abstract}

PALABRAS CLAVE: PNC. FMLN. Seguridad. Pandillas. El Salvador.

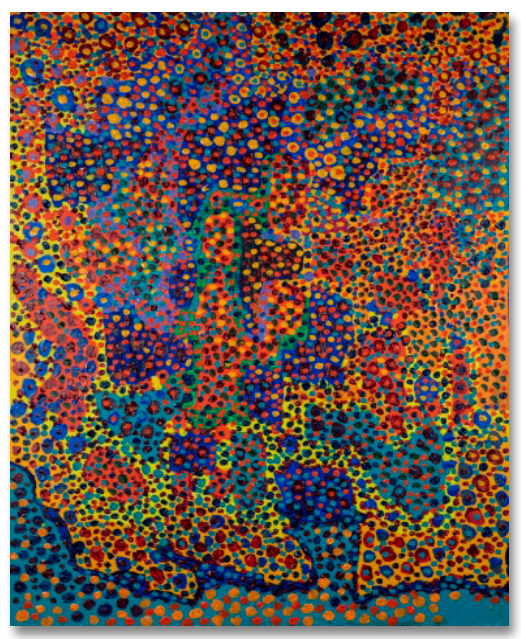

\section{The PCN of El Salvador during FMLN governments}

\section{EDgar BaLtazar LANDERos}

Estudiante del Doctorado en Ciencias Sociales y Humanísticas del Centro de Estudios Superiores de México y Centroamérica de la Universidad de Ciencias y Artes de Chiapas (Cesmeca - Unicach).

E-mail: e.baltazar.ilepaz@gmail.com.
ABSTRACT: The Peace Accords (1992) established a new institutional framework for El Salvador, including a new police. The PNC was born with the parameters of the neo-liberal doxa on the democratic police function. Throughout the postwar period, the police have not met these democratic parameters. During FMLN governments (2009-2019), the PNC failed to improve its institutional development, maintaining a war against gangs as a monothematic agenda.

KEYWORDS: PNC. FMLN. Security. Gangs. El Salvador.

RECEBIDO EM: $10 / 05 / 2019$

APROVADO EM: 26/08/2019 


\section{Introducción}

El siglo XX, en El Salvador, estuvo marcado por gobiernos militares, golpes de Estado, una alta conflictividad social y enfrentamientos armados, desembocando en la guerra que abarcó de 1980 a 1992, enfrentando al Estado salvadoreño (apoyado por los Estados Unidos) con la guerrilla del Frente Farabundo Martí para la Liberación Nacional (FMLN).

Los Acuerdos de Paz de 1992 establecieron reformas significativas en el sector de defensa y seguridad, tales como la disolución de los antiguos cuerpos represivos (Guardia Nacional, Policía Nacional y Policía de Hacienda) y creación de la Policía Nacional Civil (PNC) y de la Academia Nacional de Seguridad Pública (ANSP); así como la sustitución de la Dirección Nacional de Inteligencia por un nuevo Organismo de Inteligencia del Estado bajo mando civil, además de la reducción y depuración de la Fuerza Armada.

La institucionalidad salvadoreña naciente de los Acuerdos de Paz configura un nuevo régimen. La pacificación del país vino acompañada de la transición política y de la instauración del modelo económico neoliberal. En la posguerra, desde 1989 y hasta 2009, El Salvador vivió bajo gobiernos emanados del partido de extrema derecha, la Alianza Republicana Nacionalista (ARENA). En 2009, el FMLN, hasta entonces crítico de las políticas neoliberales, ganó por primera vez una elección presidencial, con un candidato externo a sus filas, el otrora presentador de televisión Carlos Mauricio Funes Cartagena. En 2014, el ex comandante guerrillero Salvador Sánchez Cerén se convirtió en el segundo presidente de la República postulado por el FMLN. A pesar del cambio de siglas en el ejecutivo, el neoliberalismo no pereció con la llegada de la izquierda al poder.

La instauración del neoliberalismo en El Salvador potenció la expulsión de la población marginada dadas las limitadas oportunidades económicas en el país. En años recientes, se estima en 2.5 millones el número de salvadoreños que viven en los Estados Unidos. En 2014, las remesas ascendieron a 4.217 millones de dólares, lo que equivale al 20\% del PIB (VILLAFUERTE, 2016). En 2016, las remesas totalizaron 4.576 millones de dólares; en 2017, sumaron 5.021 millones (BELLOSO, 2018), siendo esta la principal fuente de divisas para el país. 
Con relación al principal indicador de violencia, en 2018, El Salvador tuvo una tasa de homicidios de 51.7 por 100 mil habitantes, una de las más altas del mundo (DALBY; CARRANZA, 2019). El Estado salvadoreño ha sido incapaz de proveer seguridad a sus ciudadanos, su democracia es procedimental, de mercado, funcional a los triunfadores de la globalización neoliberal.

A partir de la revisión de estudios precedentes sobre la PNC (COSTA, 1999; GÓMEZ, 2017; MARTÍNEZ; FLORES, 2013; SILVA, 2014), se identifican dos procesos sustantivos para el análisis de las políticas de seguridad y su impacto en la función policial durante los dos periodos presidenciales del FMLN: 1) el rezago en el desarrollo institucional de la policía y 2) la centralidad del combate a las pandillas, como eje de la función policial. La caracterización de estos dos procesos es el objetivo de este artículo descriptivo, mediante el análisis de fuentes académicas, de prensa y de respuestas a solicitudes de información pública, escrito en el último año de gestión de Salvador Sánchez Cerén.

\section{Función policial en democracia}

La policía es una institución que, en su contacto con la sociedad, busca garantizar el consentimiento ante la autoridad estatal (BROGDEN, 1982). La relación entre Estado y policía remite al concepto de Polizeistaat (CHAPMAN, 1970), que era como, en la Prusia del siglo XVIII, se nombraba a la administración pública con el propósito de tener un gobierno estable y proteger al Estado y a sus ciudadanos. El Estado contemporáneo mantiene una relación estrecha con la policía, una institución clave para la verificación de su poder, responsable por la aplicación de la ley y por el mantenimiento del orden.

A la par de los procesos de transición a la democracia (electoral o procedimental), se comienza a concebir la pertinencia de reformas policiales. En América Latina, esto se presentó en los años ochenta y noventa del siglo XX, en paralelo al incremento de la criminalidad en la región, así como con políticas de ajuste estructural y reforma del Estado. En este contexto, emerge la concepción de la seguridad ciudadana en sustitución de la doctrina de 
seguridad nacional y de la justicia transicional como ruta en sociedades posconflicto.

El proyecto de una reforma policial acotada a la transformación de la institución en un contexto sin transformaciones estructurales en el modelo económico o en las condiciones de desigualdad busca construir un modelo civil de policía. Implica cambios doctrinarios en la concepción de las políticas de seguridad, así como transformación de la cultura policial, los procesos operativos de la policía y su propio diseño institucional (CARRIÓN, 2007; VILLALOBOS, 2007).

Retomando algunos trabajos que recuperan la doxa de las características que configuran una función policial calificada como democrática (ARIAS; ROSADA-GRANADOS; SAÍN, 2012; BADIOLA, 2011; HATHAZY, 2016; NEILD, 2001), se pueden destacar las siguientes: a) la policía como institución legítima y profesional; b) desmilitarización de las funciones de seguridad pública; c) proximidad entre policía y comunidad; d) respeto a los derechos humanos; y e) controles internos y externos de la función policial.

Lograr una función policial democrática vía reformas estatales se ha concebido prioritariamente como la adopción de normas y prácticas propias del ideario liberal: dominación legal racional, respeto a los derechos humanos y al orden jurídico vigente, transparencia y rendición de cuentas. Y como todo tipo ideal, su puesta en práctica es siempre problemática.

\section{Desarrollo institucional de la PNC}

El desarrollo institucional de la PNC ha mostrado avances y retrocesos. Mientras, por un lado, se ha avanzado en revertir el rezago existente en la carrera policial mediante la intensificación de procesos de ascenso, por el otro, prevalece claramente un conflicto interno en el nivel superior, donde aún subsisten grupos de poder emanados del conflicto armado. Hay destaque también para problemáticas vinculadas al régimen disciplinario, la infiltración criminal en la PNC y la deficiente supervisión de la función policial. 


\subsection{La policía proyectada en los acuerdos de paz}

La PNC es una institución producto de los Acuerdos de Paz, creada con el fin de resguardar la paz, la tranquilidad, el orden y la seguridad pública, tanto en el ámbito urbano como en el rural, bajo la dirección de mandos civiles. Los Acuerdos de Chapultepec, firmados el 16 de enero de 1991, establecieron que esta institución sería "un cuerpo nuevo, con nueva organización, nuevos cuadros, nuevos mecanismos de formación y adiestramiento y nueva doctrina" (ACUERDOS..., 1992, p. 528). Estos acuerdos también definieron principios democráticos para la actuación de la nueva policía, como:

[...] la noción de la seguridad pública como un servicio del Estado a la ciudadanía, ajeno a toda consideración política, ideológica o de posición social y a cualquier otra discriminación; del respeto a los derechos humanos; del esfuerzo en prevenir el delito; y de la subordinación del cuerpo a las autoridades constitucionales (ACUERDOS..., 1992, p. 529).

A 28 años de la firma de estos acuerdos, una policía con tales características parece estar aún en construcción, sobre todo ante procesos de franca militarización e infiltración criminal, además de disputas de poder al interior de una institución con déficits significativos en sus procesos de profesionalización y control interno.

\subsection{Militarización}

Tanto los gobiernos de ARENA como los del FMLN coincidieron en su impulso a la participación de la Fuerza Armada en tareas de seguridad pública, ello en contra del espíritu original de los Acuerdos Paz.

En el primer año de su mandato (2009), el presidente Mauricio Funes emitió el Decreto Ejecutivo 60, para dar continuidad a las tareas de seguridad pública de la Fuerza Armada. Con el Decreto Ejecutivo 70, se estableció la operación de Fuerzas de Tarea: patrullas militares realizando funciones propias de la policía, como registros de personas, de vehículos y arrestos en flagrancia. Esto disparó las denuncias ante la Procuraduría para la Defensa de los Derechos Humanos por abusos militares y registros invasivos. 
A mitad de su mandato, Funes había aumentado ya en un 57\% el número de elementos castrenses, pasando de 11 mil a poco más de 17mil (AMAYA, 2012).

En 2011 y 2012, personas salidas de las filas de la Fuerza Armada fueron ratificadas como Ministro de Justicia y Seguridad Publica y como Director General de la PNC, violando flagrantemente con ello los Acuerdos de Paz y el mandato constitucional de una seguridad pública bajo mando civil. Incluso un grupo de Comisionados provenientes de la ex guerrilla puso sobre la mesa su renuncia como descontento ante tales nombramientos (MARTÍNEZ, ARAUZ, 2011). Las políticas de mano dura y la violación sistemática de los derechos humanos no fueron, por tanto, monopolio de ARENA. El gobierno de Sánchez Cerén, al momento de redactar estas líneas, mantiene medidas extraordinarias para "combatir" a las maras. En 2016, se declaró emergencia en siete centros penales y se militarizaron sus perímetros (LA MILITARIZACIÓN..., 2016). En 2017, 13.920 efectivos militares realizaban labores de seguridad pública en el país (SOSA, 2017).

\subsection{Las cuotas en disputa por el poder dentro de la PNC}

La PNC nació como un nuevo campo de batalla para los bandos enfrentados en el conflicto armado. El Acuerdo de Nueva York de 1991 contempló la incorporación de combatientes del FMLN a la que sería la nueva policía. En ese mismo año, los Acuerdos de Chapultepec estipularon la disolución de la Guardia Nacional, la Policía Nacional y la Policía de Hacienda. No obstante, los grupos dominantes de esas instituciones represivas opusieron resistencia, que fue apoyada por el presidente Alfredo Cristiani, quien buscó convertir a la Guardia Nacional y a la Policía de Hacienda en una policía militar, así como incorporar a la Policía Nacional en la nueva Policía Nacional Civil. La PNC y la ANSP nacieron, entonces, bajo las zancadillas del viejo régimen. El Ejército colocó su personal en posiciones claves de la PNC (en los niveles Ejecutivo y Superior), contraviniendo con ello el espíritu de los Acuerdos de Paz. Desde su fundación, la PNC vio frustrada la implementación de una eficiente profesionalización. 
La Unidad Ejecutiva Antinarcotráfico (UEA) y la Comisión de Investigación de Hechos Delictivos (CIHD), creadas con clara injerencia norteamericana en El Salvador, durante el conflicto armado, fueron trasladadas por completo a la PNC. Esto fue avalado por el propio FMLN, quien aceptó esa incorporación a cambio de que el gobierno diera de baja a los oficiales de la Fuerza Armada enlistados por la Comisión ad hoc (COSTA, 1999). La nueva institución surgió entonces con mandos formados en la guerra. A decir de Héctor Silva (2014), la PNC nació con el "pecado original" de mantener viejas estructuras de seguridad, sobre todo dominadas por ex militares, muchos de ellos involucrados en actividades delictivas.

En el segundo gobierno del Frente, tanto el Ministro de Seguridad, Mauricio Ramírez Landaverde, como el Director General de la PNC, Howard Cotto, son policías de carrera, ex combatientes del FMLN. La PNC no tiene un registro sobre cuántos de sus integrantes actuales provienen de las cuotas del FMLN y los antiguos cuerpos de seguridad pública (CUSEP), o al menos no es información pública. ${ }^{1}$

\subsection{La infiltración de la delincuencia organizada en la PNC}

Durante los gobiernos de ARENA y en parte del primer gobierno del FMLN, los ex oficiales del Ejército dominaron las estructuras de mando dentro de la PNC. ${ }^{2}$ Por presión de Washington, el gobierno

1 En solicitud de información enviada a la Unidad de Acceso a la Información Pública de la PNC (Folio C-573-2018), fue pedido: "Número de integrantes actuales de la PNC que pertenecieron a los antiguos cuerpos de seguridad y a la ex guerrilla", teniendo como respuesta de la División de Talento Humano: "No se puede brindar lo solicitado en el literal, ya que en esta División no se lleva registro con esa clasificación". Así mismo, fue solicitado a la Oficina de Información y Respuesta de la ANSP (Folio 046): "Número de alumnos (as) que ingresaron a la ANSP, provenientes de los antiguos cuerpos de seguridad pública y de la ex guerrilla, desglose por año, sexo y categoría policial"; teniendo por respuesta: "Se aclara que la información solicitada no ha sido generada. Se conoce que los primeros ingresos posteriores al conflicto armado fueron efectuados con el apoyo de ONUSAL y COPAZ. Por el momento, existe una imposibilidad material para proporcionar o crear dicha base de datos o informe específico sobre la procedencia de los participantes (exguerrilla, ex cuerpos de seguridad o de la sociedad civil) tal como fue establecido en los Acuerdos de Paz".

2 Héctor Silva (2014) enfatiza en un grupo de oficiales de ejército que entraron a la PNC en 1993 sin siquiera haberse dado de baja de la Fuerza Armada. "Un 
de Cristiani, con la anuencia del FMLN, incorporó a la nueva policía las unidades antinarcotráfico y de investigación pertenecientes a la Policía Nacional (adscrita al Ejército), ambas infestadas de personajes vinculados a la delincuencia organizada, de acuerdo con investigaciones periodísticas como la de Silva (2014).

Mauricio Funes, primer presidente electo bajo las siglas del FMLN, a la fecha acusado de actos de corrupción, continuó con la herencia autoritaria y militarista al designar a personal castrense (vinculado y/o tolerante ante la criminalidad organizada) al frente de la cartera de seguridad, contraviniendo con ello los Acuerdos de Paz de 1992 y manteniendo la infiltración criminal al más alto nivel dentro de la PNC.

Al iniciar su gestión, Funes designó a mandos provenientes de la guerrilla como encargados de la seguridad. Nombró a Manuel Melgar al frente del Ministerio de Seguridad y a Carlos Ascencio como Director General de la PNC. Esto ocurrió con el descontento de Washington, que tenía en la mira sobre todo al Ministro Melgar, por vincularlo a la ejecución de cuatro marines norteamericanos y varios civiles en la zona rosa de San Salvador, el 19 de junio de 1985, en una operación ejecutada por un comando guerrillero del Partido Revolucionario de los Trabajadores Centroamericanos (PRTC). Fue bajo la gestión de Melgar y Ascencio que la Inspectora General, Zaira Navas, abrió expedientes contra altos mandos de la PNC involucrados con la delincuencia organizada.

Cuando la Inspectora Navas abrió expedientes contra 20 oficiales de alto rango, vinculándolos con delincuencia organizada, fue

mayor, tres capitanes, dieciocho tenientes y tres subtenientes" (SILVA, 2014, p. 27), la mayoría de ellos provenientes de la Policía Nacional, particularmente de la Unidad Ejecutiva Antinarcotráfico (UEA) y la Comisión Investigadora de Hechos Delictivos (CIHD), ambas creadas bajo el auspicio de los Estados Unidos. Mediante el Acuerdo Ejecutivo 221, fechado el 12 de mayo de 1994, pero publicado en el Diario Oficial hasta el 11 de octubre de 1995, se transfirieron a situación de reserva esos 25 oficiales militares. Todos estaban asignados a los viejos cuerpos de seguridad. Estos mandos, a decir de Silva (2014), son quienes han dominado la institución, además de que, varios de ellos, han sido señalados por vínculos con la delincuencia organizada. "Entre los que aparecen en el listado del Acuerdo 221, hay dos directores generales, dos subdirectores, seis jefes de la DAN [División Antinarcóticos]. Un jefe de la DIC [División de Investigación Criminal] y varios jefes regionales, además de dos jefes de la División de Finanzas" (SILVA, 2014, p. 29) 
objeto de persecución política por parte de los partidos de derecha, quienes, el 9 de septiembre de 2010, crearon una comisión legislativa para investigar sus supuestos abusos, misma que sería declarada inconstitucional en mayo de 2011. La Inspectora también recibió amenazas de muerte.

La esperanza de un cambio en la PNC y en la política de seguridad no se concretó, Funes designó en noviembre 2011 a los generales David Munguía Payés y Francisco Salinas al frente del Ministerio de Seguridad y la Dirección General de la PNC respectivamente, sepultando con ello los expedientes abiertos por la Inspectora Navas. Con ese movimiento, viejos mandos policiales, provenientes del Ejército y vinculados con el crimen organizado (investigados por la Inspectora Zaira Navas), regresaron a la cúpula de poder de la PNC.

De acuerdo con Silva (2014), son cuatro las garantías que han permitido la infiltración del crimen organizado en la policía salvadoreña:

- La impunidad: los órganos encargados de supervisar a la policía son débiles y son comunes los obstáculos en las investigaciones disciplinarias, como el acoso legal a testigos e investigadores. Todos los intentos de depuración policial han fracasado. ${ }^{3}$

- La élite policial: formada principalmente por oficiales de los viejos cuerpos represivos, particularmente de la UEA y la CIHD, quienes, además de algunos oficiales provenientes del FMLN, se han rotado los puestos claves de la institución desde su creación. El grupo se aglutinó originalmente bajo la figura del Mayor Óscar Armando Peña Durán; varios de

3 Silva (2014, p. 23) destaca cómo en 2001, durante la presidencia de Francisco Flores, la Asamblea Legislativa otorgó poderes plenos al entonces director de la PNC, Mauricio Sandoval, para dirigir un proceso de depuración policial. Sandoval destituyó a varios oficiales (incluyendo al Comisionado Mauricio Arriaza Chicas, nombrado Director de la PNC por Nayib Bukele), pero un fallo de la Corte Suprema de Justicia pidió su reinstalación dado lo desaseado del proceso. Silva (2014, p. 24) también refiere que en 2005-2006, durante la administración del presidente Antonio Saca, el director de la PNC, Ricardo Mauricio Menesses fue removido de su cargo y enviado a un puesto diplomático a Washington. Menesses sería dado de baja en 2010 por abandono de trabajo y no por las diversas acusaciones en su contra. 
ellos ingresaron a la PNC sin los procesos de validación y reeducación acordados. Esta élite policial ha dominado en varios momentos la División de Finanzas, área, entre otras, infiltrada por contrabandistas.

- La naturaleza misma de las redes de crimen organizado en El Salvador: existe una convivencia pacífica entre el Estado salvadoreño y el crimen organizado, particularmente los dos grupos más poderosos, Los Perrones y El Cartel de Texis.

- La entrada plena de los operadores políticos a partir de 2000: destacan las figuras de Herbert Saca, primo del presidente Antonio Saca, y de Adolfo Chele Torrez (asesinado el 2 de junio de 2009), quienes fungieron como vínculos entre el mundo criminal y el político.

La infiltración criminal en la PNC ha derivado en que la institución sea incapaz de investigar delitos de forma profesional, sobre todo cuando altos mandos se encuentran involucrados. La Inspectora Zaira Navas investigó cómo los capos de la droga no eran detenidos gracias a que había filtraciones de información, desde los más altos niveles de la PNC, sobre operativos en su contra. La impunidad ha reinado en estos casos.

\subsection{Carrera policial}

La PNC opera con un marco normativo que regula la carrera policial, con un escalafón definido, así como procesos de ingreso, ascenso y terminación del servicio. A pesar de los intentos por normar e institucionalizar un sistema de carrera policial, los decretos legislativos que permiten excepciones a las normas ${ }^{4}$ a su vez abren la puerta a la discrecionalidad. Hacerse policía no es, en la mayoría de los casos, sinónimo de hacer carrera, tampoco de un adecuado clima laboral correspondiente a los ideales de construir una policía civil tal como lo establecieron los Acuerdos de Paz. ${ }^{5}$

4 Como permitir el paso del Nivel Básico al Ejecutivo, sin necesidad de un título universitario como lo señala la legislación.

5 En un estudio reciente sobre clima laboral en la PNC, Amaya y Martínez (2016) entrevistaron a firmantes de los Acuerdos de Paz y encuestaron a Jefes 
Durante el quinquenio de Sánchez Cerén, la PNC mantuvo estable su plantilla (tabla 1), hasta alcanzar un total de 23. 313 efectivos a septiembre de $2018 .{ }^{6}$ La plantilla policial se ha mantenido dado el alto índice de bajas, sobre todo por renuncias (tabla 2).

Tabla 1 - Crecimiento de plantilla policial (2007 - 2018)

\begin{tabular}{|c|c|c|c|c|c|c|c|c|c|c|c|c|}
\hline \multirow{2}{*}{ SEXO } & \multicolumn{12}{|c|}{ AÑO } \\
\hline & 2007 & 2008 & 2009 & 2010 & 2011 & 2012 & 2013 & 2014 & 2015 & 2016 & 2017 & $2018^{*}$ \\
\hline $\begin{array}{c}\text { HOM- } \\
\text { BRE }\end{array}$ & 15,916 & 16,809 & 17.479 & 18,841 & 19,185 & 19,565 & 20,239 & 20,327 & 20,324 & 20,276 & 20,279 & 20,286 \\
\hline MUJER & 1,230 & 1,404 & 1,516 & 1,757 & 1,824 & 2,084 & 2,536 & 2,758 & 2,805 & 2,828 & 2,922 & 3,027 \\
\hline TOTAL & 17,146 & 18,213 & 18,995 & 20,598 & 21,009 & 21,649 & 22,775 & 23,085 & 23,129 & 23,104 & 23,201 & 23,313 \\
\hline
\end{tabular}

Fuente: Elaboración del autor, con base en PNC, División de Talento Humano. Respuesta de la Unidad de Acceso a la Información Pública. Folio C-573-2018

*2018, corte al 17 de septiembre.

Tabla 2 - Bajas de la PNC (2007 - agosto de 2018)

\begin{tabular}{|c|c|c|c|c|c|c|c|c|c|c|c|c|}
\cline { 2 - 15 } TIPO DE BAJA & \multicolumn{10}{|c|}{ AÑO } \\
\cline { 2 - 15 } & $\mathbf{2 0 0 7}$ & $\mathbf{2 0 0 8}$ & $\mathbf{2 0 0 9}$ & $\mathbf{2 0 1 0}$ & $\mathbf{2 0 1 1}$ & $\mathbf{2 0 1 2}$ & $\mathbf{2 0 1 3}$ & $\mathbf{2 0 1 4}$ & $\mathbf{2 0 1 5}$ & $\mathbf{2 0 1 6}$ & $\mathbf{2 0 1 7}$ & $\mathbf{2 0 1 8}^{*}$ \\
\hline RENUNCIA & 226 & 156 & 74 & 80 & 119 & 169 & 202 & 242 & 358 & 360 & 190 & 190 \\
\hline FALLECIMIENTO & 30 & 36 & 32 & 41 & 46 & 41 & 39 & 54 & 90 & 69 & 51 & 51 \\
\hline DESTITUCIÓN & 243 & 104 & 115 & 61 & 64 & 39 & 73 & 50 & 68 & 52 & 38 & 38 \\
\hline TOTAL & $\mathbf{4 9 9}$ & $\mathbf{2 9 6}$ & $\mathbf{2 2 1}$ & $\mathbf{1 8 2}$ & $\mathbf{2 2 9}$ & $\mathbf{2 4 9}$ & $\mathbf{3 1 4}$ & $\mathbf{3 4 6}$ & $\mathbf{5 1 6}$ & $\mathbf{4 8 1}$ & $\mathbf{3 5 1}$ & $\mathbf{4 3 7}$ \\
\hline
\end{tabular}

Fuente: Elaboración del autor, con base en PNC, División de Talento Humano. Respuesta de la Unidad de Acceso a la Información Pública. Folio C-573-2018

*2018, corte al 17 de septiembre.

En la plantilla actual (al redactar este texto, el segundo semestre de 2018) de la PNC (tabla 3), 95.8\% de los policías pertenecen al nivel básico, $3.4 \%$ al nivel ejecutivo y $0.6 \%$ al nivel superior. Del total de personal operativo, el $83 \%$ es agente; $87 \%$ son hombres y 13\% mujeres. De enero de 2014 a agosto de 2018, 1667 integrantes de la PNC lograron ascender: ${ }^{7} 583$ a la categoría de cabo, 450 a sargento, 360 a subinspector, 22 a inspector, 121 a inspector jefe, 31 a subcomisionado y nadie a comisionado.

de Delegaciones policiales; demostrando la existencia de obstáculos para la consolidación de un modelo policial civil que se anteponga a uno militarizado. 6 PNC. Respuesta de la Unidad de Acceso a la Información Pública. Folio C-573-2018.

7 PNC. Respuesta de la Unidad de Acceso a la Información Pública. Folio C-573-2018. 
Tabla 3 - Plantilla de la PNC al 17 de septiembre de 2018

\begin{tabular}{|c|c|c|c|c|}
\hline \multicolumn{2}{|c|}{ CATEGORÍA POLICIAL } & HOMBRE & MUJER & TOTAL \\
\hline \multirow{2}{*}{ Nivel Superior } & Comisionado & 49 & 9 & $\mathbf{5 8}$ \\
\cline { 2 - 5 } & Subcomisionado & 85 & 12 & $\mathbf{9 7}$ \\
\hline \multirow{3}{*}{ Nivel Ejecutivo } & Inspector Jefe & 108 & 15 & $\mathbf{1 2 3}$ \\
\cline { 2 - 5 } & Inspector & 159 & 11 & $\mathbf{1 7 0}$ \\
\cline { 2 - 5 } & Subinspector & 459 & 49 & $\mathbf{5 0 8}$ \\
\hline \multirow{3}{*}{ Nivel Básico } & Sargento & 1,062 & 63 & $\mathbf{1 , 1 2 5}$ \\
\cline { 2 - 5 } & Cabo & 1,720 & 148 & $\mathbf{1 , 8 6 8}$ \\
\cline { 2 - 5 } & Agente & 16,644 & 2,720 & $\mathbf{1 9 , 3 6 4}$ \\
\hline TOTAL GENERAL & & 20,286 & 3,027 & $\mathbf{2 3 , 3 1 3}$ \\
\hline
\end{tabular}

Fuente: Elaboración del autor, con base en PNC, División de Talento Humano. Respuesta de la Unidad de Acceso a la Información Pública. Folio C-573-2018

Según cifras oficiales de la PNC (tabla 4), de enero de 2006 a agosto de 2018, 330 policías salvadoreños han perdido la vida víctimas de homicidio. El 61,5\% de dichas muertes han ocurrido de 2014 a 2018, siendo el año 2015 el que presentó el máximo histórico de asesinatos de policías.

Tabla 4 - Estadística de integrantes de la PNC fallecidos (homicidios), segregado por sexo (2006 - agosto de 2018)

\begin{tabular}{|c|c|c|c|c|c|c|c|c|c|c|c|c|c|c|}
\hline \multirow{2}{*}{ SEXO } & \multicolumn{10}{|c|}{} & \multirow{2}{*}{ TOTAL } \\
\cline { 2 - 14 } & $\mathbf{2 0 0 6}$ & $\mathbf{2 0 0 7}$ & $\mathbf{2 0 0 8}$ & $\mathbf{2 0 0 9}$ & $\mathbf{2 0 1 0}$ & $\mathbf{2 0 1 1}$ & $\mathbf{2 0 1 2}$ & $\mathbf{2 0 1 3}$ & $\mathbf{2 0 1 4}$ & $\mathbf{2 0 1 5}$ & $\mathbf{2 0 1 6}$ & $\mathbf{2 0 1 7}$ & $\mathbf{2 0 1 8}$ & \\
\hline HOMBRE & 12 & 11 & 16 & 18 & 17 & 17 & 15 & 14 & 39 & 61 & 46 & 41 & 16 & 323 \\
\hline MUJER & & & & & 1 & & & & & 3 & 1 & 2 & & 7 \\
\hline TOTAL & $\mathbf{1 2}$ & $\mathbf{1 1}$ & $\mathbf{1 6}$ & $\mathbf{1 8}$ & $\mathbf{1 8}$ & $\mathbf{1 7}$ & $\mathbf{1 5}$ & $\mathbf{1 4}$ & $\mathbf{3 9}$ & $\mathbf{6 4}$ & $\mathbf{4 7}$ & $\mathbf{4 3}$ & $\mathbf{1 6}$ & $\mathbf{3 3 0}$ \\
\hline
\end{tabular}

Fuente: PNC. Respuesta de la Unidad de Acceso a la Información Pública. Folio C-573-2018

Del total de integrantes de la PNC asesinados de enero de 2006 a agosto de 2018, 2,7\% laboraba como personal administrativo, 4,2\% empleados supernumerarios, 92,1\% policías de escala básica (270 agentes, 24 cabos y 10 sargentos), 0,6\% de escala ejecutiva (1 subinspector y 1 inspector) y $0,3 \%$ de escala superior (1 subcomisionado). Si bien la proporción de la plantilla policial es superior a los otros niveles, es claro que el riesgo de morir asesinado es mucho mayor para los agentes que para sus mandos. En la serie histórica proporcionada, ${ }^{8}$ la PNC no reporta la muerte por homicidio de algún comisionado.

8 PNC. Respuesta de la Unidad de Acceso a la Información Pública. Folio C-573-2018. 
Las y los policías salvadoreños no gozan de adecuadas condiciones de trabajo, lo que incluso ha derivado en protestas por parte del personal (CAMPOS, 2018). La salud mental del personal de la PNC es atendida por apenas 33 psicólogos (CASTRO, 2018). Entre los años 2015 y 2016, se suicidaron 10 policías (CASTRO, 2018). La PNC no goza de estabilidad laboral y su profesionalización se ve seriamente amenazada por condiciones adversas para su personal. A partir de las medidas extraordinarias, los policías salvadoreños exponen cada vez más sus vidas, a cambio reciben un bono trimestral de 300 dólares, para completar un salario que, en el caso de los agentes (nivel más bajo de la escala jerárquica), asciende a alrededor de 450 dólares mensuales.

Las condiciones de las mujeres policía son más adversas que las de sus compañeros varones, pues ellas se enfrentan a la agravante de una violencia de género institucionalizada, la misma que se expresa en casos graves como la desaparición de la agente Carla Ayala a manos de policías del ahora extinto Grupo de Reacción Policial (GRP) 9 y el asesinato de la agente Lorena Hernández, perpetrado por su pareja, también policía, en instalaciones de la propia PNC (ambos casos ocurridos en diciembre de 2017). También se han registrado casos de violaciones y abusos sexuales en inspecciones médicas en la Academia Nacional de Seguridad Pública (ANSP). Las mujeres representan el 13\% del personal policial y sólo el 9\% del personal del nivel ejecutivo (VALENCIA, 2018).

\subsection{Control policial}

En 2013, se reformó el Código Procesal Penal para flexibilizar el control sobre el personal de seguridad pública; desde entonces, el fiscal tiene 72 horas para imputar a un uniformado, si no lo hace durante ese lapso, existe sobreseimiento de cargos (CALLAMARD, 2018). Durante el quinquenio de Sánchez Cerén, la PNC ha abierto

9 Tras el caso de la agente Carla Ayala, la PNC disolvió al GRP, pero en febrero de 2018 anunció la creación de un nuevo cuerpo especial: la Unidad Táctica Especializada Policial (UTEP), conocida como "Jaguares". La agente Ayala estuvo desaparecida desde el 29 de diciembre de 2017 y sus restos fueron encontrados por la PNC el 7 de septiembre de 2018 (CALDERÓN, 2018). 
menos expedientes disciplinarios contra personal policial que en el de Mauricio Funes, aunque se destaca que, de enero a agosto de 2018, se abrieron más investigaciones contra comisionados que en los cuatro años anteriores.

Tabla 5 - Casos disciplinarios contra personal policial (2009 - agosto de 2018)

\begin{tabular}{|l|l|l|l|l|l|l|l|l|l|l|}
\hline \multicolumn{1}{|c|}{ CATEGORÍA } & $\mathbf{2 0 0 9}$ & $\mathbf{2 0 1 0}$ & $\mathbf{2 0 1 1}$ & $\mathbf{2 0 1 2}$ & $\mathbf{2 0 1 3}$ & $\mathbf{2 0 1 4}$ & $\mathbf{2 0 1 5}$ & $\mathbf{2 0 1 6}$ & $\mathbf{2 0 1 7}$ & $\mathbf{2 0 1 8}$ \\
\hline Comisionado & 8 & 12 & 1 & 3 & 3 & 1 & 3 & 1 & 2 & 8 \\
\hline Subcomisionado & 0 & 1 & 0 & 2 & 3 & 6 & 6 & 8 & 11 & 12 \\
\hline Inspector Jefe & 8 & 13 & 0 & 3 & 7 & 1 & 2 & 0 & 4 & 6 \\
\hline Inspector & 11 & 18 & 13 & 15 & 29 & 16 & 4 & 8 & 8 & 8 \\
\hline Subinspector & 28 & 50 & 43 & 16 & 14 & 28 & 20 & 18 & 18 & 23 \\
\hline Sargento & 17 & 30 & 36 & 58 & 28 & 23 & 8 & 23 & 30 & 15 \\
\hline Cabo & 38 & 47 & 64 & 53 & 41 & 21 & 23 & 24 & 29 & 33 \\
\hline Agente & 300 & 384 & 562 & 412 & 346 & 324 & 263 & 278 & 270 & 255 \\
\hline Administrativo & 25 & 55 & 14 & 20 & 28 & 12 & 20 & 50 & 15 & 11 \\
\hline TOTAL & $\mathbf{4 3 5}$ & $\mathbf{6 1 0}$ & $\mathbf{7 3 3}$ & $\mathbf{5 8 2}$ & $\mathbf{4 9 9}$ & $\mathbf{4 3 2}$ & $\mathbf{3 4 9}$ & $\mathbf{4 1 0}$ & $\mathbf{3 8 7}$ & $\mathbf{3 7 1}$ \\
\hline
\end{tabular}

Fuente: PNC. Respuesta de la Unidad de Acceso a la Información Pública. Folio C-573-2018.

En noviembre de 2014, se creó la Inspectoría General de Seguridad Pública (IGSP) como ente externo a la PNC, responsable de realizar investigaciones disciplinarias sobre faltas cometidas por el personal de la PNC y la ANSP. Esta nueva institución, dependiente del Ministerio de Justicia y Seguridad Pública, sustituye a la Inspectoría General de la Policía Nacional Civil (IGPNC), que era un órgano de control interno y, por tanto, sólo con competencia sobre la PNC, mientras que la IGSP también tiene competencia sobre la ANSP.

La IGPNC tenía bajo su dependencia a las unidades de Control (UC), Investigación Disciplinaria (UID), Asuntos Internos (UAI) y de Derechos Humanos (UDH); las cuales, ante la creación de la IGSP, pasaron a depender de la nueva Secretaría de Responsabilidad Profesional de la PNC (creada en febrero de 2016), salvo la Unidad de Derechos Humanos que pasó a la Secretaría de Relaciones con la Comunidad (GÓMEZ, 2017). La IGSP tiene facultad fiscalizadora para aplicar el régimen disciplinario y supervisar que la conducta de la PNC sea ética y apegada a los derechos humanos, pero, en la perspectiva de Gómez (2017), no tiene aún una vinculación eficiente con las unidades de control interno de la PNC.

En su análisis sobre las condiciones institucionales de la IGSP, Gómez (2017) destaca las dificultades de ésta para administrar su propio presupuesto, su déficit de personal y falta de capacidad 
técnica para procesar información. Identifica también como problemático el hecho de que la Sala de lo Constitucional de la Corte Suprema de Justicia haya emitido la resolución de que no se pueden hacer investigaciones disciplinarias por delito investigados penalmente (GÓMEZ, 2017). Esto en el contexto de un giro de la PNC hacia un carácter preponderantemente represivo.

De marzo de 2015 a abril de 2018, la IGSP ha iniciado un total de 6.553 investigaciones disciplinarias y ha remitido 97 casos a la Fiscalía General de la República. ${ }^{10}$ De 2015 a marzo de 2018, se han dado 10.951 sanciones (tabla 6.), presentando una evidente disminución en las mismas durante los dos últimos años. Destaca que, en dicho periodo, en el nivel superior, sólo ocho subcomisionados han sido suspendidos; ningún comisionado o subcomisionado ha sido destituido. ${ }^{11}$

Tabla 6 - Personal policial sancionado (2015 - marzo de 2018)

\begin{tabular}{|l|l|l|l|l|}
\hline \multicolumn{1}{|c|}{ SANCIONES } & $\mathbf{2 0 1 5}$ & $\mathbf{2 0 1 6}$ & $\mathbf{2 0 1 7}$ & $\mathbf{2 0 1 8}$ \\
\hline Destitución & 140 & 184 & 153 & 32 \\
\hline Suspensión sin goce de sueldo* & 916 & 1,625 & 661 & 40 \\
\hline TOTAL & $\mathbf{1 , 0 5 6}$ & $\mathbf{1 , 8 0 9}$ & $\mathbf{8 1 4}$ & $\mathbf{7 2}$ \\
\hline
\end{tabular}

Fuente: Elaboración del autor, con información de respuesta a solicitud de información remitida a la Unidad de Acceso a la Información Pública de la IGSP, Folio IGSP-2018-014.

*Incluye suspensión por faltas muy graves (91-180 días) y graves (16-90 días y arrestos de 4-5 días).

De enero a septiembre de 2017, 559 agentes policiales fueron detenidos por diversos delitos (EL SALVADOR..., 2017).

\section{Las pandillas como centro de la actuación policial}

La función policial en El Salvador pareciera monotemática, pues las maras ocupan el lugar prioritario de las acciones de la PNC, en un contexto que privilegia la represión. Históricamente, la narrativa oficial de la PNC ha sido identificar a las maras MS-13

10 Solicitud de información remitida a la Unidad de Acceso a la Información Pública de la IGSP, Folio IGSP-2018-014.

11 Solicitud de información remitida a la Unidad de Acceso a la Información Pública de la IGSP, Folio IGSP-2018-014. 
y Barrio 18, dividida en sureños y revolucionarios, como las principales amenazas a la seguridad, sin referir a otras estructuras del crimen organizado. Así, durante la gestión de los generales Munguía Payés y Salinas, no hubo una estrategia clara de combate al crimen organizado y sí una centralidad de la problemática de las pandillas. Cuando los generales dirigieron la política de seguridad, se dejó de investigar particularmente al Cartel de Texis y a Los Perrones, las dos organizaciones criminales más poderosas de El Salvador. Es en este periodo en que, de la mano de Munguía Payés, se gestó la tregua entre las maras, un proceso que implicó un distanciamiento con Washington, que otrora apoyaba al General.

Durante el quinquenio de Mauricio Funes, la apuesta gubernamental para hacer frente al problema de inseguridad y violencia fue pactar con las pandillas. Este proceso, apoyado por el Ejecutivo, entró en crisis y fue abandonado en el segundo periodo presidencial del FMLN. La negociación cambió por el combate frontal. Esto tuvo una importante incidencia en el perfil de la actuación policial, pues se abandonó la apuesta por la proximidad social para privilegiar un modelo represivo. Si bien las medidas extraordinarias en centros penales decretadas en el gobierno de Salvador Sánchez Cerén se acotaron al ámbito carcelario, discursivamente y en la práctica, estas configuraron el perfil de la respuesta gubernamental ante la problemática prevaleciente de inseguridad y violencia.

La Mara Salvatrucha-13 es la pandilla más grande del país, se estima en 40.000 el número de sus integrantes, quienes recaudan alrededor de 30 millones de dólares anuales por pagos de extorsiones (AHMED, 2017). Junto con sus rivales del Barrio 18 (en sus fracciones sureños y revolucionarios, con alrededor de 20,000 integrantes),"12 conforman una "mafia de pobres que desangra a El Salvador" (MARTÍNEZ et. al., 2016, [s.p.]). Las maras comenzaron a instalarse en El Salvador fundamentalmente en la década de los noventa (MARTÍNEZ; FLORES, 2013), cuando Estados Unidos deportó masivamente a pandilleros, sobre todo desde Los Ángeles.

12 Se estima que 500,000 personas ( $8 \%$ de la población total), forma la red de apoyo de las pandillas (CALLAMARD, 2018). 
Durante los gobiernos de Francisco Flores (1999 - 2004) y Antonio Saca (2004 - 2009), ambos de ARENA, la respuesta ante el problema de las pandillas fue, explícitamente, de mano dura. En julio de 2003, Flores anunció el Plan Mano Dura; en octubre del mismo año se aprobaría la Ley Antimaras, vigente hasta abril de 2004, cuando la Corte Suprema de Justicia la declaró inconstitucional (MARTÍNEZ; FLORES, 2013). Elías Antonio Saca anunció, en agosto de 2004, el Plan Súper Mano Dura e impulsó una ley contra el crimen organizado; esto, paradójicamente, se acompañó de intentos de programas de reinserción y prevención, como los planes Mano Amiga y Mano Extendida (MARTÍNEZ; FLORES, 2013).

Estas políticas de mano dura, lejos de disminuir la actividad delictiva de las pandillas, agravaron los niveles de violencia ejercidos por estas. En 2005, durante el gobierno de Saca, los principales líderes de las pandillas son trasladados al penal de máxima seguridad de Zacatecoluca, desde donde consolidaron su liderazgo. En febrero de 2006, las pandillas demostraron su capacidad para hacer política; entonces, la MS-13 difundió un comunicado donde exigía el cese del Plan Súper Mano Dura, pidiendo el respeto a sus derechos humanos, acusaban a la PNC y a empresas privadas de tener grupos de exterminio (MARTÍNEZ; FLORES, 2013).

Las pandillas tienen amplia presencia en el territorio, abarcando 247 de los 262 municipios del país; se les atribuyen dos tercios de los homicidios que ocurren (CALLAMARD, 2018). Se estima que los $70 \%$ de los comercios pagan extorsiones ${ }^{13}$ (MARTÍNEZ et. al., 2016). Esos recursos alimentan una economía delictiva de subsistencia. La mayor parte de los líderes pandilleros operan tras las rejas.

Las maras ejercen control al organizarse a varios niveles. La MS-13 se organiza con una dirección de líderes internacionales y nacionales, quienes dirigen a los ranfleros, que pueden ser

13 Entre 2013 y 2015, 424 pandilleros fueron sentenciados por el delito de extorsión. En 2015, 154 conductores de transporte público fueron asesinados por negarse al pago de extorsiones de, en promedio, un dólar al día. Los pandilleros parecen obtener más recursos por extorsión que por otras actividades como la venta de droga. Entre 2011 y 2015, la PNC confiscó a las maras sólo 13,9 kilogramos de cocaína, lo que representa menos del uno por ciento del total incautado (MARTÍNEZ et. al., 2016). 
corredores de programas (conjunto de clicas dirigidas por un palabrero e integradas a su vez por soldados). El Barrio 18, por su parte, también tiene una ranfla nacional como máximo órgano y, en lugar de programas, llama tribus a los conjuntos de canchas con su propio líder e integradas por soldados (MARTÍNEZ; FLORES, 2013). Para 2013, la PNC tenía registro de 279 clicas de la MS-13, que conformaban 48 programas y 167 canchas del Barrio-18, que integraban 28 tribus (MARTÍNEZ; FLORES, 2013).

\subsection{La tregua de Funes}

Las primeras acciones de Mauricio Funes contra las pandillas continuaron con la línea de mano dura. En noviembre de 2009, se militarizó la seguridad en los centros penales, el cual derivó en múltiples quejas por violaciones a los derechos humanos de presos y familiares (MARTÍNEZ; FLORES, 2013). En septiembre de 2010, se publicó la ley de proscripción de pandillas, como respuesta ante el atentado terrorista de la pandilla Barrio-18, en el municipio de Mejicanos, cuando ésta, en junio de ese año, incendió un microbús con 20 pasajeros dentro.

Cuando el General Munguía Payés tomó las riendas del Ministerio de Justicia y Seguridad Pública, la estrategia cambió; se optó por la negociación secreta con los líderes pandilleriles. En marzo de 2012, el periódico digital El Faro (MARTínEZ et.al., 2012) reveló cómo el gobierno de Funes negoció con las maras la reducción de homicidios. Alrededor de 30 líderes pandilleros fueron trasladados del penal de máxima seguridad de Zacatecoluca hacia penales ordinarios; entre ellos, los máximos dirigentes de la MS-13 y el Barrio 18. Así, los líderes de las pandillas pudieron tener contacto físico con personas del exterior, lo que favoreció que dirigieran órdenes para que líderes de programas y tribus dieran la instrucción, a las clicas y canchas, de parar los homicidios. De acuerdo con El Faro, citando como fuentes a informantes del Centro de Inteligencia Policial (CIP) y del Organismo de Inteligencia del Estado (OIE), el gobierno incluso ofreció dinero a los pandilleros de más alto rango para la disminución de los homicidios. En su inicio, la tregua fue dirigida por el coronel Simón 
Molina Montoya (entonces segundo al mando del OIE), del círculo cercano de Munguía Payés (PANDILLERO ..., 2017).

Tras la revelación de El Faro, el Ministerio de Justicia y Seguridad manifestó que el traslado obedeció a razones humanitarias (MARTÍNEZ; FLORES, 2013), mientras Monseñor Fabio Colindres y el ex combatiente y ex diputado del FMLN, Raúl Mijango, declararon que ellos fungieron como mediadores para la tregua. Incluso la Organización de Estados Americanos (OEA) avaló la tregua; su Secretario General, José Miguel Insulza, se reunió en julio de 2012 con integrantes de pandillas en el penal de Mariona, quienes le entregaron una propuesta de desarme parcial. Insulza presenció la entrega de 77 armas de fuego por parte de la MS-13 y el Barrio 18 en un acto realizado en la plaza cívica de San Salvador, el 13 de julio de 2012. Para entonces, en el primer semestre de 2012, ya se contabilizaban 532 homicidios menos que en el primer semestre de 2011 (MARTÍNEZ, FLORES, 2013). Durante la tregua, se pasó de un promedio de 13 homicidios diarios a un aproximado de cinco (MARTÍNEZ; FLORES, 2013). Fue clara la reducción de los homicidios en los años 2012 y 2013, ${ }^{14}$ pero no así la incidencia delictiva, sobre todo las extorsiones. Los líderes pandilleros, ya en penales con menos control, podían administrar los cobros de extorsiones y dirigir órdenes a sus subalternos en la calle.

En noviembre de 2012, los mediadores de la tregua pusieron en marcha una segunda fase del proceso, consistente en la declaración de zonas especiales de paz, mediante el concepto de "municipios santuarios" (MARTÍNEZ; FLORES, 2013, p. 20). Esto, se anunció, iniciaría en 10 municipios para después ampliarse a 18.

La tregua, que en 2012 y buena parte de 2013 permitió una reducción de homicidios atribuibles a las pandillas, con el apoyo de la presidencia de la República, el Ministerio de Justicia y Seguridad Pública, la OEA y autoridades locales, acabó de ser sepultada por Sánchez Cerén desde que tomó el poder en 2014. Desde entonces, las pandillas han sido combatidas como grupos terroristas y sus principales cabecillas fueron trasladados de nueva cuenta a penales de máxima seguridad.

14 La tasa de homicidios en 2012 fue de 41.2, 29.7 en 2013, 62.2 en 2014, 105.8 en 2015, 83.9 en 2016 y 64 en 2017. Cf. SSPAS (2015, 2016), IML (2017), García y Segura (2018). 
Mientras el ex presidente Funes sigue en libertad y su Ministro de Justicia y Seguridad Pública, David Munguía Payés, fue Ministro de Defensa del presidente Sánchez Cerén, Raúl Mijango, facilitador de la tregua, ha sido condenado a 13 años con cuatro meses de prisión por el delito de extorsión agravada en complicidad con las maras. Esto con base en el señalamiento de un testigo criteriado (protegido) (LUNA, 2018).

\subsection{Las medidas extraordinarias de Sánchez Cerén}

El primero de abril de 2016, la Asamblea Legislativa de El Salvador emitió el Decreto no 321, intitulado "Disposiciones especiales transitorias y extraordinarias en los centros penitenciarios, granjas penitenciarias, centros intermedios y centros temporales de reclusión". Las medidas extraordinarias contempladas en dicho decreto son la habilitación de centros temporales de reclusión, traslados entre centros penitenciarios, encierro en celdas especiales, restricción de visitas y participación obligatoria en actividades de índole "reeducativa".

Las medidas, reprobadas por la Organización de las Naciones Unidas (ONU) (BARRERA, 2018; CALLAMARD, 2018; GARCÍA, 2018; RELATORA..., 2018), también incluyen la suspensión de traslados para audiencias (mismas que se llevan a cabo vía videoconferencia), además de cortar el tráfico de telecomunicaciones en los centros penitenciarios. Las medidas, de origen, tenían un plazo de un año, pero se fueron prorrogando hasta tornarse en permanentes (GÓMEZ, 2018).

El Estado salvadoreño atribuye a las maras una proporción significativa de la violencia criminal contra la población, entre ellas mismas y contra agentes estatales. De acuerdo con información proporcionada por la PNC (tabla 7.), de enero de 2006 a agosto de 2018, del total de 330 policías víctimas de homicidio, el 48,7\% fueron asesinados por pandillas; de estos, 60,2\% son homicidios atribuibles a la Mara Salvatrucha y 39,7\% a la pandilla Barrio 18, en sus diferentes escisiones. 


\begin{tabular}{|c|c|c|c|c|c|c|c|c|c|c|c|c|c|c|}
\hline \multirow{2}{*}{$\begin{array}{c}\text { TIPO DE } \\
\text { PANDILLA DEL } \\
\text { HECHOR }\end{array}$} & \multicolumn{13}{|c|}{ AÑo } & \multirow[b]{2}{*}{ TOTAL } \\
\hline & 2006 & 2007 & 2008 & 2009 & 2010 & 2011 & 2012 & 2013 & 2014 & 2015 & 2016 & 2017 & 2018 & \\
\hline MS & 1 & & 2 & 4 & 1 & 10 & 5 & 4 & 13 & 13 & 19 & 22 & 3 & 97 \\
\hline P-18 & 1 & & & 1 & & 3 & 2 & 3 & 3 & 11 & 1 & & & 25 \\
\hline P-18R & & & & & & & & & 7 & 11 & & 3 & 1 & 22 \\
\hline P-18S & & & & & & & & & 6 & 1 & 5 & 2 & 1 & 15 \\
\hline MAO MAO & & & & & & & 1 & & & 1 & & & & 2 \\
\hline N/D & 10 & 11 & 14 & 13 & 17 & 4 & 7 & 7 & 10 & 27 & 22 & 16 & 11 & 169 \\
\hline TOTAL & 12 & 11 & 16 & 18 & 18 & 17 & 15 & 14 & 39 & 64 & 47 & 43 & 16 & 330 \\
\hline
\end{tabular}

Fuente: PNC. Respuesta de la Unidad de Acceso a la Información Pública. Folio C-573-2018.

Nota de la PNC: el dato proporcionado es según casos iniciados, por lo que es de carácter preliminar y podría variar ya que determinar datos de los victimarios corresponde al proceso de investigación individual de cada caso.

La criminalización y el combate a las pandillas han sido acompañados de un incremento en las violaciones a los derechos humanos. ${ }^{15}$ Con las medidas extraordinarias en centros penales, las personas privadas de libertad sólo tienen permitido tomar el sol una hora tres veces por semana, pero, en algunos casos, incluso ese "derecho" ha sido suspendido. Ningún pandillero preso ha tenido visitas de familiares desde la ejecución de las medidas extraordinarias (PDDH, 2017). La atención médica para estos reclusos es precaria (PDDH, 2017), por ejemplo, sólo existen dos psiquiatras para toda la población penitenciaria a nivel nacional. De enero a diciembre de 2016, se registraron 422 casos de tuberculosis en los siete centros penales donde se aplican las medidas extraordinarias (PDDH, 2017); la cifra aumentó a 1.272 personas con dicha enfermedad en enero de 2018 (además, 137 presentaban síntomas) (CALLAMARD, 2018). A pesar del endurecimiento del control penitenciario, de enero a noviembre de 2016, murieron 47 hombres en prisiones salvadoreñas; 19 fallecieron por alguna enfermedad, 16 fueron víctimas de homicidio (delitos no investigados) $\mathrm{y}$, en 12 casos, no se especifica la causa (PDDH, 2017). En 2017, murieron 127 personas en cárceles salvadoreñas (CALLAMARD, 2018).

15 En 2016, la Procuraduría para la Defensa de los Derechos Humanos (PDDH) recibió 1,012 denuncias contra la Policía Nacional Civil y 192 contra la Fuerza Armada. Incluidas 27 denuncias por ejecuciones (PDDH, 2017). 
Las medidas extraordinarias han implicado una disminución en homicidios atribuidos a las pandillas, pero no así de otros delitos como la extorsión, amenazas y lesiones (PDDH, 2017). Los pandilleros en prisión se encuentran en encierro permanente, de modo que no son objeto de acciones de tratamiento y la afectación de sus derechos generó en 2016 "más de dos mil intervenciones de la PDDH [Procuraduría para la Defensa de los Derechos Humanos] en los centros penitenciarios" (PDDH, 2017, p. 29).

Las medidas extraordinarias no son sólo penitenciarias, a pesar de que el Decreto 221 se restringe a ello. ${ }^{16}$ Las medidas son también policiales y ocupan el lugar central en el discurso gubernamental en cuanto a su política de seguridad. ${ }^{17}$ Desde 2014, los altos mandos policiales aprobaron que los agentes lleven su arma de cargo a sus domicilios y la utilicen si es el caso.

De 2013 a septiembre de 2017, la Procuraduría para la Defensa de los Derechos Humanos (PDDH) registró 159 supuestas ejecuciones extrajudiciales cometidas por los cuerpos de seguridad en El Salvador (OPERACIONES..., 2017), a partir de sus propias investigaciones y la identificación de patrones de uso de la fuerza letal. Durante el quinquenio de Salvador Sánchez Cerén, destacó la centralidad de la represión policial como estrategia contra las maras, incurriendo en violaciones graves a los derechos humanos. Dentro de los casos que ha recuperado la prensa salvadoreña, destaca la operación de un grupo de las Fuerzas Especiales de Reacción El Salvador (FES) como escuadrón de la muerte, involucrado con ejecuciones, abusos sexuales y extorsión, develado en agosto de 2017 por la revista Factum (AVELAR; MARTÍNEZ, 2017), así como la documentación que realizó el periódico digital El Faro, sobre una masacre perpetrada por el Grupo de Reacción Policial (GRP) en la finca cafetalera San Blas, donde ocho

16 Como lo ha reconocido la ONU, las medidas extraordinarias incluyen, además de las penitenciarias, la participación del ejército en tareas de seguridad pública, la creación de nuevos delitos y la reforma a la Ley penal juvenil (CALLAMARD, 2018).

17 Esto a pesar de que, en 2015, el gobierno de Sánchez Cerén adoptó el plan El Salvador Seguro, que incluye una serie de medidas de prevención en los 50 municipios más violentos del país. 
personas fueron ejecutadas extrajudicialmente en marzo de 2015 (VALENCIA; MARTÍNEZ; VALENCIA, 2015). Entre enero y agosto de 2016, por cada policía que murió asesinado fueron asesinados 53 presuntos pandilleros en supuestos tiroteos con la policía (AHMED, 2017), siendo este un índice de letalidad evidentemente desproporcionado.

De 2014 a 2016, se investigaron 41 casos de participación de policías en grupos de exterminio (CALLAMARD, 2018); para 2018, 24 de estos casos habían sido desestimados, diez continuaban en investigación, seis eran seguidos por la Inspectoría General y sólo una persona había sido sancionada.

Las unidades élite de la policía salvadoreña, acusadas de participar en ejecuciones extrajudiciales (PATON; ARVANDITIDIS; AVELAR, 2018) han recibido apoyo económico de los Estados Unidos. La FES, por ejemplo, fue una unidad que tan sólo de enero a junio de 2017 estuvo involucrada en al menos 43 ejecuciones de presuntos pandilleros (PATON; ARVANITIDIS; AVELAR, 2018). La FES fue creada en abril de 2016, disuelta junto con el GRP, en febrero de 2018 (después del caso Carla Ayala), y se integraba por 1.000 miembros (400 policías élite y 600 militares). Además de FES, el gobierno creó las Fuerzas de Intervención y Recuperación de Territorios (FIRT), el Grupo Conjunto de Apoyo a la Comunidad (GCAC) y la Fuerza de Tarea "Centro Histórico", todos grupos policiales militarizados (CALLAMARD, 2018).

En febrero de 2018, se crean los Jaguares con alrededor de 200 miembros, algunos de la FES y otros del Grupo de Operaciones Especiales (GOPES), también disuelto en febrero de 2018. Los Jaguares tienen soporte económico norteamericano. En los Jaguares no se incorporaron a integrantes del extinto GRP (LÓPEZ, 2018), quienes fueron asignados a tareas de seguridad pública y dejaron de percibir el bono de entre 120 y 160 dólares que recibían como incentivo por pertenecer a la unidad élite responsable, entre otros delitos, de la desaparición de Carla Ayala y el encubrimiento de sus perpetradores.

De acuerdo con la Relatora Especial sobre Ejecuciones Extrajudiciales de la ONU, Agnes Callamard (2018), el 92\% de las investigaciones contra policías son desestimadas en las primeras 
72 horas. La relatora destaca en su informe un patrón de ejecuciones extrajudiciales. De enero a mayo de 2018, sólo un policía había sido sentenciado por ejecución extrajudicial. Según la relatora, mientras en 2014 murieron 103 presuntos pandilleros en enfrentamientos con la policía, la cifra subió considerablemente en 2016, cuando 591 presuntos pandilleros fueron asesinados en enfrentamientos y 119 resultaron heridos. La PNC se ha negado a reconocer que esas muertes formen parte de un patrón de ejecuciones o "exterminio", como se ha calificado desde la prensa (LA POLICÍA..., 2018). La Fiscalía General ha solicitado el sobreseimiento de los cargos en más de la mitad de los casos de presuntas ejecuciones extrajudiciales o uso excesivo de la fuerza por parte de la PNC y la Fuerza Armada (CALLAMARD, 2018)

Además de la violencia extrema de las ejecuciones sumarias, las detenciones arbitrarias y torturas son moneda de cambio de los cuerpos élite que participan en la guerra contra las pandillas (MARTÍNEZ, 2015a, 2015b), llegando incluso a incomunicar a detenidos por hasta seis meses, sin permitirles contacto con familiares o abogados (RAUDA, 2017).

\section{Conclusiones}

A la luz de los reportes de la prensa y estudios académicos sobre la Policía Nacional Civil de El Salvador, no parece haber indicios de que ésta cumpla con los parámetros de una función policial democrática, tales como el respeto irrestricto a los derechos humanos, la profesionalización del personal y los controles sobre su actuación. La policía diseñada en los Acuerdos de Paz no ha encontrado su concreción en la realidad.

La PNC se topó con el problema de una sociedad en proceso de reconstrucción, con la vigencia de desigualdades que potenciaron el conflicto armado y, sobre todo, con una generación de jóvenes sin acceso a oportunidades educativas y laborales, quienes terminarían engrosando las filas de las pandillas. El Estado salvadoreño en general y la policía en particular se vieron rebasados por la problemática y, ante ella, han reaccionado con acciones represivas y no de transformación estructural. Esta línea no ha 
distinguido colores partidistas, pues ha sido la misma tanto para los gobiernos de derecha como para la experiencia del FMLN en el poder. Esa preponderancia represiva se observa incluso en la indefinición ideológica del gobierno de Nayib Bukele; quien, con su anunciado Plan Control Territorial, ha reeditado los planes de mano dura y ha potencializado las medidas extraordinarias y la militarización características de los gobiernos del Frente.

Tanto los gobiernos de ARENA como los del FMLN centraron la actuación policial en acciones punitivas, sobre todo ante la problemática de las pandillas. El FMLN tuvo la oportunidad de marcar un cambio de rumbo en la institución, sin embargo, lo que hizo fue abonar a la profundización de la militarización emprendida por gobiernos anteriores. Las cuotas que, desde un inicio se disputaron el control de la PNC, son vigentes hoy en día. Mauricio Arriaza Chicas, nuevo Director General de la PNC con el entrante gobierno de Nayib Bukele, por ejemplo, proviene de la extinta Policía Nacional.

La PNC no es una institución libre de miembros de la delincuencia organizada, varios de los cuales, según los casos documentados por Silva (2014), son fundadores de ella. Los intentos de depuración policial han sido infructuosos. Si bien en los gobiernos del FMLN se intentó atender el desarrollo institucional de la policía, con la implementación de mecanismos de profesionalización y control policial, el contexto de la guerra contra las pandillas y la impunidad de altos mandos probablemente vinculados con actividades delictivas han incidido en que, hoy en día, la policía salvadoreña no sea un símbolo de paz.

Mientras Mauricio Funes impulsó un pacto secreto con las pandillas, que permitió una reducción significativa en las tasas de homicidio, con Salvador Sánchez Cerén dominó un perfil represivo por parte de la policía. La mano dura de los gobiernos de ARENA fue profundizada por un gobierno que hizo de la excepción la regla. El Salvador aún no ha conocido un proyecto progresista de seguridad ni una refundación de su institución policial. Pensar la seguridad de la mano de los diferentes sectores sociales, priorizar la prevención sobre la represión y depurar a la policía son aún tareas pendientes. 


\section{REFERENCIAS}

ACUERDOS de Chapultepec. Biblioteca Jurídica Virtual de UNAM, [on line], 16 ene. 1991. Disponible en: <https://archivos.juridicas.unam.mx/ www/bjv/libros/4/1575/23.pdf>. Acceso en: 1 ago. 2019.

AHMED, A. La hora de la verdad en El Salvador. New York Times, [on line], 29 nov. 2017. Disponible en: <https://www.nytimes.com/es/2017/11/29/ el-salvador-maras-tregua-violencia/>. Acceso en: 19 jun. 2018.

AMAYA, E. Militarización de la seguridad pública en El Salvador, 19922012. URVIO - Revista Latinoamericana de Seguridad Ciudadana, Quito, n. 12, p. 71 - 82, 2012.

AMAYA, L. E.; MARTÍNEZ, J. J. Una aproximación al clima organizacional en la Policía Nacional Civil (PNC) de El Salvador. Revista Policía y Seguridad Pública, Santa Tecla, a. 6, v. 2, p. 269 - 306, 2016.

ARIAS, P.; ROSADA-GRANADOS, H.; SAÍN, M. F. Reformas policiales en América Latina: principios y lineamientos progresistas. Bogotá: Friedrich Ebert Stiftung, 2012.

AVELAR, B.; MARTÍNEZ, J. En la intimidad del escuadrón de la muerte de la policía. Revista Factum, El Salvador, 22 ago. 2017. Disponible en: $<$ http://revistafactum.com/en-la-intimidad-del-escuadron-de-la-muertede-la-policia/>. Acceso en: 19 jun. 2018

BADIOLA, I. Función policial, democracia y accountability. Revista Logos

- Ciencia \& Tecnología, Bogotá, D.C., v. 2, n. 2, p. 188 - 201, 2011.

BARRERA, E. Funcionarios reconocen ejecuciones: relatora ONU. La Prensa Gráfica, San Salvador, 6 feb. 2018. Disponible en: <https://www. laprensagrafica.com/elsalvador/Funcionarios-reconocen-ejecucionesrelatora-ONU-20180205-0125.html>. Acceso en: 3 oct. 2018.

BELLOSO, M. Remesas familiares superaron en 2017 los $\$ 5,000$ millones. La Prensa Gráfica, San Salvador, 18 ene. 2018. Disponible en: <https:// www.laprensagrafica.com/economia/Remesas-familiares-superaron-en2017-los-5000-millones-20180117-0125.html>. Acceso en: 29 jun. 2018.

BROGDEN, M. The Police: Autonomy and Consent. London-New York: Academic Press, 1982.

CALDERÓN, B. "Los restos de Carla Ayala no fueron encontrados por casualidad": ¿Cómo fue localizada la policía desaparecida hace meses? La Prensa Gráfica, San Salvador, 11 sep. 2018. Disponible en: <https:// www.laprensagrafica.com/elsalvador/Los-restos-de-Carla-Ayala-nofueron-encontrados-por-casualidad-Como-fue-localizada-la-policiadesaparecida-hace-meses-20180911-0013.html>. Acceso en: 17 oct. 2018. 
CALLAMARD, A. Declaración final de misión en El Salvador: relatora especial sobre las ejecuciones extrajudiciales, sumarias o arbitrarias de Naciones Unidas. [s.l.]: [s.n.], 2018.

CAMPOS, F. Supuestos policías bloquearon autopista Los Chorros y generaron caos vehicular. El Diario de Hoy, San Salvador, 16 oct. 2018. Disponible en: <https://www.elsalvador.com/fotogalerias/noticiasfotogalerias/529067/supuestos-policias-bloquean-autopista-los-chorrosy-generan-caos-vehicular/>. Acceso en: 17 oct. 2018.

CARRIÓN, F. Reforma policial: ¿Realidad ineludible de una nueva doctrina de seguridad? URVIO - Revista Latinoamericana de Seguridad Ciudadana, Quito, n. 2, p. 5 - 22, 2007.

CASTRO, C. ¿Qué sucede con los policías en El Salvador? El Salvador Times, San Salvador, 6 ene. 2018. Disponible en: <http:// www.elsalvadortimes.com/articulo/sucesos/sucede-policiassalvador/20180102184743034186.html>. Acceso en: 17 oct. 2018.

CHAPMAN, B. Police State. London: Pall Mall Press, 1970.

COSTA, G. La Policía Nacional Civil de El Salvador (1990-1997). San Salvador: UCA Editores, 1999.

DALBY, C.; CARRANZA, C. Balance de InSight Crime sobre los homicidios en 2018. InSigth Crime, [on line], 22 ene. 2019. Disponible en: <https:// es.insightcrime.org/noticias/analisis/balance-de-insight-crime-sobrelos-homicidios-en-2018/>. Acceso en: 13 jun. 2019.

EL SALVADOR: ya van 559 agentes de policía detenidos en 2017. Deutsche Welle, [on line], 11 sep. 2017. Disponible en: <http://www.dw.com/ es/el-salvador-ya-van-559-agentes-de-polic\%C3\%ADa-detenidos-en2017/a-40454784>. Acceso en: 19 jun. 2018.

GARCÍA, G. PDDH apela ante ONU por medidas extraordinarias. La Prensa Gráfica, San Salvador, 27 ene. 2018. Disponible en: <https://www. laprensagrafica.com/elsalvador/PDDH-apela-ante-ONU-por-medidasextraordinarias-20180126-0113.html>._Acceso en: 25 dic. 2018.

GARCÍA, G.; SEGURA, E. El Salvador es el país con más homicidios de Centroamérica. La Prensa Gráfica, San Salvador, 3 ene. 2018. Disponible en: <https://www.laprensagrafica.com/elsalvador/El-Salvador-es-elpais-con-mas-homicidios-de-Centroamerica-20180102-0444.html>. Acceso en: 29 jun. 2018.

GÓMEZ, J. R. Control y supervisión de la Policía Nacional Civil: Estudio institucional de la Inspectoría General de Seguridad Pública. Revista Policía y Seguridad Pública, Santa Tecla, a. 7, v. 1, p. 173 - 236, 2017.

GÓMEZ, R. Con 71 votos se aprueba que medidas extraordinarias en sistema penitenciario sean permanentes. La Prensa Gráfica, San Salvador, 16 ago. 2018. Disponible en: <https://www.laprensagrafica.com/elsalvador/ 
Con-71-votos-se-aprueba-que-medidas-extraordinarias-en-sistemapenitenciario-sean-permanentes-20180816-0080.html>. Acceso en: 3 oct. 2018.

HATHAZY, P. Democratización y campo policial: nuevos consensos, cambios estructurales y mutaciones organizacionales en las policías de Chile (1990-2005). Civitas - Revista de Ciências Sociais, Porto Alegre, v. 16, n. 4, p. $595-617,2016$.

IML - Instituto de Medicina Legal. Reconocimientos realizados por médicos forenses del Instituto de Medicina Legal, practicados a personas fallecidas en hechos de violencia (homicidios), ocurridos en El Salvador en el año 2016. El Salvador: [s.n.], 2017.

LA MILITARIZACIÓN de la seguridad pública. Diario El Mundo, San Salvador, 2 abr. 2016. Disponible en: <http://elmundo.sv/la-militarizacionde-la-seguridad-publica/>. Acceso en: 4 may. 2018.

LA POLICÍA de El Salvador niega que EE.UU. financie un "exterminio" de pandilleros. Agencia EFE, [on line], 31 may. 2018. Disponible en: <https:// www.efe.com/efe/america/portada/la-policia-de-el-salvador-niega-que-eeuu-financie-un-exterminio-pandilleros/20000064-3633474\#>. Acceso en: 21 oct. 2018.

LÓPEZ, J. Agentes GRP excluidos de nueva unidad élite PNC. Elsalvador. com, San Salvador, 14 feb. 2018. Disponible en: <https://www.elsalvador. $\mathrm{com} /$ noticias/nacional/449916/agentes-grp-excluidos-de-nueva-unidadelite-pnc/>. Acceso en: 21 oct. 2018.

LUNA, S. Raúl Mijango fue condenado a 13 años de prisión por extorsión. Elsalvador.com, San Salvador, 12 oct. 2018. Disponible en: <https://www. elsalvador.com/noticias/nacional/527831/raul-mijango-condenado-a13-anos-de-prision-por-delito-de-extorsion/>. Acceso en: 12 nov. 2018.

MARTínEZ, C. ¿Vamos a la guerra? El Faro, San Salvador, 9 abr. 2015 [2015a]. Disponible en: <http://salanegra.elfaro.net/es/201504/ bitacora/16828/\%C2\%BFvamos-a-la-guerra.htm>. Acceso en: 19 jun. 2018.

MARTÍNEZ, O. "Aquí ya no caben más: mátenlos". El Faro, San Salvador: 2 jul. 2015 [2015b]. Disponible en: <https://salanegra.elfaro.net/es/201507/ cronicas/17148/Aqu\%C3\%AD-ya-no-caben-m\%C3\%A1s-m\%C3\%A1tenlos. htm>. Acceso en: 19 jun. 2018.

MARTÍNEZ, O.; ARAUZ, S. Un grupo de jefes policiales pretende renunciar si Munguía Payés toma Ministerio de Seguridad. El Faro, San Salvador, 18 nov. 2011. Disponible en: <https://www.elfaro.net/es/201111/ noticias/6645/>. Acceso en: 19 jun. 2018. 
MARTínEZ, O. et al. Gobierno negoció con pandillas reducción de homicidios. El Faro, San Salvador, 14 mar. 2012. Disponible en: <https:// elfaro.net/es/201203/noticias/7985/Gobierno-negoci\%C3\%B3-conpandillas-reducci\%C3\%B3n-de-homicidios.htm>. Acceso en: 25 dic. 2018.

La mafia de pobres que desangra a El Salvador. New York Times, [on line], 21 nov. 2016. Disponible en: <https://www.nytimes.com/ es/2016/11/21/la-mafia-de-pobres-que-desangra-el-salvador/>. Acceso en: 19 jun. 2018.

MARTÍNEZ, C. A.; FLORES, J. L. H. La tregua entre pandillas: una amenaza o una oportunidad para la seguridad pública en El Salvador. Trabajo de graduación del primer curso de ascenso para optar al grado de Subcomisionado de la Policía Nacional Civil, ANSP, San Luis Talpa, El Salvador, 2013.

NEILD, R. Democratic police reforms in war-torn societies. Conflict, Security \& Development, Londres, v. 10, n. 1, p. 21 - 43, 2001.

OPERACIONES policiales contra las maras en Honduras y El Salvador. Deutsche Welle, [on line], 12 sep. 2017. Disponible en: <http://www. dw.com/es/operaciones-policiales-contra-las-maras-en-honduras-y-elsalvador/a-40457863>. Acceso en: 19 jun. 2018.

PANDILlERO MS en oficina de Inteligencia de Fuerza Armada. La Prensa Gráfica, San Salvador, 27 abr. 2017. Disponible en: <https://www. laprensagrafica.com/elsalvador/Pandillero-MS-en-oficina-de-Inteligenciade-Fuerza-Armada-20170427-0069.html>. Acceso en: 12 nov. 2018.

PATON, N.; ARVANITIDIS, B.; AVELAR, B. A. US-funded police linked to ilegal executions in El Salvador. CNN World, [on line], 2018. Disponible en: <https://edition.cnn.com/interactive/2018/05/world/el-salvador-policeintl/>. Acceso en: 21 oct. 2018.

PDDH - Procuraduría para la Defensa de los Derechos Humanos. Informe preliminar sobre el impacto de las medidas extraordinarias para combatir la delincuencia, en el ámbito de los derechos humanos. San Salvador: PPDH, 2017.

RAUDA, N. Chungo y Toño, los jóvenes que pasaron seis meses desaparecidos en manos de la policía de El Salvador. BBC Mundo, [on line], 21 nov. 2017. Disponible en: <http://www.bbc.com/mundo/noticiasamerica-latina-40592536>. Acceso en: 19 jun. 2018.

RELATORA ONU recomienda quitar medidas extraordinarias en penales. La Prensa Gráfica, San Salvador, 5 feb. 2018. Disponible en: <https:// www.laprensagrafica.com/elsalvador/Relatora-ONU-recomienda-quitarmedidas-extraordinarias-en-penales-20180205-0073.html>. Acceso en: 3 oct. 2018. 
SILVA, H. Infiltrados: crónica de la corrupción en la PNC (1992-2013). San Salvador: UCA Editores, 2014.

SOSA, R. ¿Por qué no es militarización de la seguridad pública el plan San Salvador? La Prensa Gráfica, San Salvador, 23 sep. 2017. Disponible en: <https://www.laprensagrafica.com/opinion/ Por-que-no-es-militarizacion-de-la-seguridad-publica-el-Plan-SanSalvador-20170922-0181.html>. Acceso en: 4 may. 2018.

SSPAS - Servicio Social Pasionista del Observatorio de Derechos Humanos. Informe de violaciones a derechos humanos 2014. San Salvador: Servicio Social Pasionista, 2015.

Informe de violaciones a derechos humanos 2015. San Salvador: Servicio Social Pasionista, 2016.

VALENCIA, R. Las mujeres que llevan el uniforme de Carla Ayala. El Faro, San Salvador, 8 mar. 2018. Disponible en: <https://elfaro.net/es/201803/ salanegra/21635/Las-mujeres-que-llevan-el-uniforme-de-Carla-Ayala. htm>. Acceso en: 19 jun. 2018.

VALENCIA, R.; MARTÍNEZ, O.; VALENCIA, D. La Policía masacró en la finca San Blas. El Faro, San Salvador, 22 jul. 2015. Disponible en: <http://www.salanegra.elfaro.net/es/201507/cronicas/17205/LaPolic\%C3\%ADa-masacr\%C3\%B3-en-la-finca-San-Blas.htm>. Acceso en: 19 jun. 2018.

VILLAFUERTE, D. El Triángulo Norte de Centroamérica: dilemas de la democracia en una subregión conflictiva. In: GARCíA, M. del C.; SOLÍS, J.; UC, P. (coords.). Democracias posibles: crisis y resignificación - Sur de México y Centroamérica. México: Unicach-Cesmeca, 2016. p. 99 - 121.

VILLALOBOS, L. Enfoque institucional para la reforma policial y la rendición de cuentas. URVIO - Revista Latinoamericana de Seguridad Ciudadana, Quito, n. 2, p. 57 - 70, 2007. 